Check for updates

Department of Respiratory and Sleep Medicine, St Vincent's University Hospital, Dublin, Republic of Ireland

2 School of Medicine, University College Dublin, Dublin, Republic of Ireland

Correspondence to M W Butler marcus.butler@ucd.ie

Cite this as: BMJ 2021;375:n2355 http://dx.doi.org/10.1136/bmj.n2355 Published: 04 October 2021

\title{
THERAPEUTICS
}

\section{Treatments for poorly controlled asthma}

\author{
Orla O'Carroll, ${ }^{1}$ Cormac McCarthy, ${ }^{1,2}$ Marcus W Butler', 2
}

What you need to know

- In a patient with worsening symptoms of asthma, confirm the diagnosis and address possible causes of worsening, including treatment adherence, comorbidities, and environmental factors

- Combined inhaled corticosteroids with long acting $\beta$ agonists (LABA) as single maintenance and reliever therapies are associated with reduced exacerbations and improved asthma related quality of life compared with traditional dual maintenance and reliever therapies

- LABA monotherapy is not recommended owing to increased risk of exacerbations and asthma related death

- Written asthma plans given to patients as part of a supported self-management strategy help reduce hospitalisation and emergency department attendances

A 35 year old man with a prior diagnosis of mild asthma presents to his general practitioner with a three month history of intermittently waking at night with cough and shortness of breath. He works as a chef and has found it difficult to complete a full shift during this time. He has been prescribed beclometasone $200 \mu \mathrm{g}$ twice a day for a long time and asks if there is a need to change his treatment in light of his new persistent symptoms.
Poorly controlled or moderate asthma occurs when patients experience either daily symptoms of asthma, nocturnal awakenings, more than two exacerbations per year, or some limitation of their daily activities. ${ }^{12}$ With frequent alterations of guidelines, and continual development of new medications and delivery devices, choosing a suitable treatment strategy can pose a challenge in clinical practice. In this article, we present the latest guidance on drugs used in primary care for poorly controlled asthma in adults.

\section{What treatments are available for poorly controlled asthma?}

\section{ICS/LABA combination}

Inhaled corticosteroids (ICS, eg, beclometasone dipropionate, budesonide, fluticasone furoate, etc) and long acting $\beta$ agonists (LABA, eg, formoterol, salmeterol, vilanterol, etc) are the mainstay of treatment for poorly controlled or moderate asthma (table 1). ICS suppress airway inflammation leading to reduced bronchial hyperresponsiveness. LABAs act on bronchial smooth muscle $\beta$ adrenoceptors and cause bronchodilation. ICS and LABA are typically prescribed as a single fixed dose combination inhaler rather than in separate inhalers for better efficacy, safety, adherence, and convenience. ${ }^{1}$

Table 1 | Global Initiative for Asthma treatment ladder $^{1}$

\begin{tabular}{|c|c|c|c|c|c|}
\hline & Step 1 & Step 2 & Step 3 & Step 4 & Step 5 \\
\hline $\begin{array}{l}\text { Preferred controller } \\
\text { (ie, maintenance } \\
\text { therapy) }\end{array}$ & $\begin{array}{l}\text { As-needed low dose } \\
\text { ICS-formoterol }\end{array}$ & $\begin{array}{l}\text { Daily low dose ICS or } \\
\text { as-needed low dose } \\
\text { ICS-formoterol }\end{array}$ & Low dose ICS-LABA & Medium dose ICS-LABA & $\begin{array}{l}\text { High dose ICS-LABA. } \\
\text { Refer for phenotypic } \\
\text { assessment } \pm \text { add-on } \\
\text { therapy, eg, tiotropium, } \\
\text { anti-IgE, anti-IL5/5R, } \\
\text { anti-IL4R }\end{array}$ \\
\hline $\begin{array}{l}\text { Other controller } \\
\text { options }\end{array}$ & $\begin{array}{c}\text { Low dose ICS taken } \\
\text { whenever SABA is } \\
\text { taken }\end{array}$ & $\begin{array}{c}\text { Daily LTRA or low dose } \\
\text { ICS whenever SABA } \\
\text { taken }\end{array}$ & $\begin{array}{l}\text { Medium dose ICS or } \\
\text { low dose ICS+LTRA }\end{array}$ & $\begin{array}{c}\text { High dose ICS, add-on } \\
\text { tiotropium, or add-on } \\
\text { LTRA }\end{array}$ & $\begin{array}{l}\text { Add low dose OCS but } \\
\text { consider side effects }\end{array}$ \\
\hline Other reliever option & As-needed SABA & As-needed SABA & As-needed SABA & As-needed SABA & As-needed SABA \\
\hline
\end{tabular}

$I C S=$ inhaled corticosteroids; $L A B A=$ long acting $\beta$ agonists; $L T R A=$ leukotriene receptor antagonist; $O C S=$ oral corticosteroids; $S A B A=$ short acting $\beta$ agonist 
National and international guidelines-Global Initiative for Asthma, ${ }^{1}$ National Institute for Health and Care Excellence (NICE), ${ }^{3}$ British Thoracic Society/Scottish Intercollegiate Guidelines Network, ${ }^{4}$ and the National Asthma Education and Prevention Program (American) ${ }^{5}$-suggest two options for commencing ICS and LABA treatments in moderate persistent asthma. The Single Maintenance and Reliever Therapy (SMART or MART) protocol recommends ICS and a fast acting LABA as both maintenance and rescue treatment for relief from symptoms (for example, low dose budesonide-formoterol or beclomethasone-formoterol). ${ }^{1}$ Alternatively, ICS plus LABA (ICS/LABA) can be combined with a short acting $\beta$ agonist (SABA) as needed as reliever treatment.

\section{Montelukast}

The guidelines recommend montelukast in patients whose symptoms are not well controlled despite adequate dosing of ICS/LABA treatments and good adherence. ${ }^{1-35}$ Montelukast is a leukotriene receptor antagonist (LTRA). It blocks the production of cysteinyl leukotrienes which are potent broncho-constricting and proinflammatory mediators. This results in enhanced bronchodilation and reduced airway mucus production. ${ }^{6}$

\section{Newer treatments}

Patients whose asthma is severe and poorly controlled with the above drugs can be considered for newer add-on treatments. These include long acting muscarinic antagonists (LAMAs), azithromycin, and biological therapies. ${ }^{12-9}$ They are usually prescribed in specialist settings after careful evaluation of a patient's symptoms, and consideration of risks and benefits.

\section{How well do they work?}

Two Cochrane reviews published in 2013 compared budesonide and formoterol as maintenance and reliever therapy (MART) with inhaled corticosteroids alone or as combination therapy for maintenance with any reliever treatment for chronic asthma. ${ }^{10} 11$ SMART was associated with reduced exacerbation rates requiring hospitalisation or emergency department visits (odds ratio (OR) 0.72, 95\% confidence interval (CI) 0.57 to $0.90 ; \mathrm{I}^{2}=0 \%, \mathrm{P}=0.66$ ), oral corticosteroids (OR $0.75,95 \% \mathrm{CI} 0.65$ to $0.87 ; \mathrm{I}^{2}=0 \%, \mathrm{P}=0.82$ ) and lower overall ICS total daily dose. ${ }^{11}$ The strength of evidence that SMART reduces hospitalisations or emergency department visits is weak (one fewer per 100 treated than in the control group, $95 \% \mathrm{CI}$, o to 2 fewer). ${ }^{1011}$ Two fewer people needed a course of oral steroids per 100 treated ( $95 \%$ CI 1 to 3 fewer) with SMART compared with alternative regimens. Two randomised controlled trials (RCTs) published in 2013 showed similar results with use of the SMART regimen. ${ }^{1213}$ Most studies are industry sponsored, and do not include children and adolescents. A post-hoc analysis of industry sponsored trials reported similar efficacy and safety for SMART regimens in adolescents (12-17 years). ${ }^{14}$ Few studies have directly compared the efficacy of various ICS preparations and have shown comparable effects. $^{15}$

Very limited evidence is available for montelukast in patients with poorly controlled asthma. An open label industry sponsored trial
(1681 participants) reported that addition of oral montelukast to ICS or ICS+LABA improved asthma control and asthma related quality of life over six months in adults with insufficiently controlled asthma. ${ }^{16}$ LTRAs have been shown to decrease sputum eosinophilia, ${ }^{17}$ fraction of exhaled nitric oxide, ${ }^{18}$ airway inflammation, ${ }^{19}$ and bronchial hyperresponsiveness, ${ }^{20}$ but the clinical relevance of these outcomes is not established. LTRAs may have a role in managing exercise induced asthma, ${ }^{21} 22$ aspirin exacerbated respiratory disease (which includes non-steroidal anti-inflammatory drug intolerance), ${ }^{23}$ and in patients with asthma and elevated body mass index, ${ }^{24}$ but this evidence comes from small single studies.

\section{What are the harms?}

Few studies assess the risk of systemic adverse effects associated with the use of ICS in asthma. A Cochrane review found that the rate of serious adverse events (eg, hospitalisation, intensive care admission, intubation) was 23 per 1000 patients in a pooled analysis of patients taking ICS plus salmeterol compared with 21 per 1000 patients taking ICS alone. ${ }^{25}$ ICS is generally considered safe at low to medium doses ( $<1000 \mu \mathrm{g}$ beclomethasone dipropionate equivalent per day). ${ }^{26}$ Local side effects include dysphonia and oral candidiasis. These can be mitigated with careful attention to oral or throat hygiene, good inhaler technique, and the preferential use of spacer devices or valved holding chambers to reduce oropharyngeal deposition.

Higher doses of ICS are associated with systemic side effects; in particular, adrenal insufficiency. About $6.8 \%$ of patients on ICS experience adrenal insufficiency, according to a systematic review. ${ }^{27}$ These doses are not routinely used for treatment of mild to moderate asthma but some patients may be on higher cumulative doses before treatment is escalated in response to persistent symptoms. NICE recommends that patients on high dose ICS (>1000 $\mu \mathrm{g} /$ day beclomethasone dipropionate or $1600 \mu \mathrm{g} /$ day for budesonide or equivalent) carry a steroid warning card. ${ }^{3}$

LABA monotherapy is associated with an increased risk of severe asthma attacks leading to hospitalisation and asthma related death, ${ }^{28-30}$ and is discouraged by all major asthma guidelines. ${ }^{13-5}$ LABAs are combined with ICS in all fixed dose combination inhalers to prevent substitution of ICS maintenance therapy with LABA monotherapy. ${ }^{25} 31$

Montelukast can have neuropsychiatric adverse effects including nightmares, aggression, and depression. ${ }^{32}$ A case series reported development of eosinophilic granulomatosis with polyangiitis with use of LTRAs, sometimes linked to weaning of corticosteroids, but causation has not been established. ${ }^{33}$

\section{How are they given and monitored?}

Confirm the diagnosis of asthma in any patient with worsening symptoms, ideally by observing for reversible airflow limitation. Table 2 lists aspects to cover on initial assessment and potential causes of reduced asthma control to address before considering a change in medication. 7-934 $35^{-15}$ 
Table 2 | Care of a patient with worsening symptoms ${ }^{1}$

\begin{tabular}{|c|c|}
\hline Action & Consideration \\
\hline Confirm the diagnosis is correct & $\begin{array}{l}\text { Does the patient have previously documented reversible airflow obstruction? } \\
\text { If not, aim to establish same: } \\
\quad \text { - Peak flow meter showing variation of }>20 \% \text { overall or mean diurnal variation }>10 \% \\
\text { over at least } 7 \text { consecutive days with twice-daily best-of-three readings over the course of } 2-4 \\
\text { weeks } \\
\text { - Bronchodilator reversibility }>12 \% \text { and } 200 \mathrm{ml} \text { on spirometry with reversibility } \\
\text { If both above negative, consider referral to asthma centre for bronchial challenge testing and } \\
\text { fraction of exhaled nitric oxide measurement (as per local guidance) }\end{array}$ \\
\hline Assess for inhaler related problems & $\begin{array}{l}\text { Is the patient taking their inhalers regularly as prescribed? } \\
\text { Is the patient taking their inhalers correctly? } \\
\text { - Assess inhaler technique }\end{array}$ \\
\hline Assess for comorbid conditions & $\begin{array}{l}\text { Does the patient have features of any of the following conditions? } \\
\text { - Rhinitis } \\
\text { - Sinusitis } \\
\text { - Gastroesophageal reflux } \\
\text { - Vocal cord dysfunction } \\
\text { - Atopy/allergy } \\
\text { - Cardiovascular disease } \\
\text { - Obstructive sleep apnoea } \\
\text { - Anxiety }\end{array}$ \\
\hline Assess for changes in environment & $\begin{array}{l}\text { Have there been any changes to the patient's environment? } \\
\text { - Smoking } \\
\text { - Weight gain } \\
\text { - New pets } \\
\text { - Exposure to new allergens } \\
\text { - Change in occupation }\end{array}$ \\
\hline
\end{tabular}

If a change in medication is indicated, prescribe ICS/LABA combinations at the lowest dose of ICS possible to achieve symptomatic control. The aims of treatment are to minimise disruptive symptoms, improve the patient's asthma related quality of life, and prevent exacerbations and worsening. Most inhaled corticosteroids are prescribed for use twice daily. Ciclesonide is a once daily preparation associated with lower incidence of oral candidiasis compared with fluticasone at equivalent doses. ${ }^{36}$ Fluticasone furoate is a once daily preparation available in some countries, including the US and Japan, as a standalone ICS and is more widely available as a combination ICS/LABA (vilanterol) inhaler preparation. Arrange a regular review to assess symptom control.

Choosing the appropriate inhaler device for a patient is important to optimise dosing schedule, adherence to therapy, and avoidance of critical errors in inhaler technique. ${ }^{37}$ When switching from single to combination inhalers, ensure that the equivalent ICS dosing is not lower than the patient's current treatment.

With SMART regimens daily dosing varies in response to symptoms. Guidelines recommend a maximum safe daily dose. ${ }^{1}$ Dosing is capped at $72 \mu \mathrm{g}$ metered dose for budesonide-formoterol and $48 \mu \mathrm{g}$ metered dose for beclomethasone-formoterol. Provide patients with a written action plan tailored to the specific ICS prescribed, outlining how to change their dosing schedule in response to symptom triggers including exacerbation. Self-management involves patient education reinforced by an asthma action plan and supported by regular review. A meta-review (27 systematic reviews and 13 RCTs) showed that supported self-management for asthma can reduce hospitalisations, emergency department attendances, and unscheduled consultations in specialist and primary care. ${ }^{38}$

Given the uncertain benefits of montelukast and potential adverse reactions, discuss the risks and benefits with your patient before commencing this medication.

\section{How cost effective are they?}

Few studies have compared cost effectiveness of individual ICS. A review article suggested that fluticasone propionate was associated with a marginal cost benefit over budesonide, but this effect was not seen at higher doses of ICS. ${ }^{39}$ An analysis of cost effectiveness in the UK and other European countries in 2006 found that SMART is more cost effective compared with the alternative dosing strategy of LABA/ICS plus SABA reliever. ${ }^{40}$ The current availability of generic preparations suitable for use in SMART protocols will have reduced the costs further.

The cost of inhaler devices can differ and can sometimes be a barrier to compliance. Discuss with your patient the expected costs when choosing a suitable inhaler device. Sustainability is another factor in inhaler choice. Metered dose inhalers (MDIs) contain hydrofluorocarbons, which are potent greenhouse gases that contribute significantly to the carbon footprint. A simple switch from MDI to equivalent dry powder inhaler (DPI) could reduce the yearly carbon footprint of an asthmatic patient by a similar amount as would be achieved by switching to a plant based diet (approximately $455 \mathrm{CO} 2$ equivalent).

\section{Tips for patients}

- Always take your asthma medication as prescribed

- Your doctor may provide written advice (asthma action plan) on how to change how often you take your inhaler if you develop symptoms or feel an asthma attack coming on. It's important to recognise changes in your symptoms so that you can follow this asthma plan correctly

- Peak flow meters can be useful when changing your inhaler frequency according to your asthma plan

- Inhalers can sometimes be difficult to use. If you have any doubt about how to take your inhaler, contact your pharmacist or GP 
- Some inhalers can cause fungal infections in the mouth (white coating of your mouth or tongue) and this may require medication to treat. Report this to your doctor

- Rinse your mouth after taking your inhaler if it contains an inhaled steroid. This can prevent fungal mouth infections from developing

\section{Education into practice}

- How would you assess an asthmatic patient with worsening symptoms to determine if therapy needs to be escalated?

- How do you assess inhaler technique in your consultation with asthmatic patients?

- How would you explain the SMART regimen to your patients?

- How would you facilitate self-management at your practice at an institutional level for people with asthma, ideally in a way that is regularly audited to facilitate ongoing service improvement?

\section{How patients were involved in the creation of this article}

We asked three patients who attend our asthma service to review a draft of this manuscript and to help develop the "tips for patients" box. They highlighted the importance of understanding symptom control and knowing when to seek help from their practitioner for troublesome symptoms.

Advisers to this series are Robin Ferner, honorary professor of clinical pharmacology, University of Birmingham and Birmingham City Hospital, and Patricia McGettigan, clinical senior lecturer in clinical pharmacology, Queen Mary's University, London

Competing interests: Competing interests The $B M$ / has judged that there are no disqualifying financial ties to commercial companies. The authors declare the following other interests: none.

Further details of The BMJ policy on financial interests are here: https://www.bmj.com/about-bmj/resources-authors/forms-policies-and-checklists/declaration-competing-interests

Provenance and peer review: commissioned, based on an idea from the authors.

Global Initiative for Asthma (GINA). 2020 GINA Report, Global strategy for asthma management and prevention. 2020.

2 Williams SG, Schmidt DK, Redd SC, Storms WNational Asthma Education and Prevention Program. Key clinical activities for quality asthma care. Recommendations of the National Asthma Education and Prevention Program. MMWR Recomm Rep 2003;52(RR-6):1-8.pmid: 12696781

3 National Institute for Health and Care Excellence. 2018 exceptional surveillance of asthma: diagnosis, monitoring and chronic asthma management (NICE guideline NG80). 2018 https://www.nice.org.uk/guidance/ng80/resources/2018-exceptional-surveillance-of-asthmadiagnosis-monitoring-and-chronic-asthma-management-nice-guideline-ng806599448397/chapter/Surveillance-decision?tab=evidence

4 Smith D, Du Rand IA, Addy C, etal. British Thoracic Society guideline for the use of long-term macrolides in adults with respiratory disease. BMJ Open Respir Res 2020;7:e000489. doi: 10.1136/bmjresp-2019-000489 pmid: 32332022

5 Expert Panel Working Group of the National Heart, Lung, and Blood Institute (NHLBI) administered and coordinated National Asthma Education and Prevention Program Coordinating Committee (NAEPPCC)Cloutier MM, Baptist AP, etal. 2020 focused updates to the asthma management guidelines: a report from the National Asthma Education and Prevention Program Coordinating Committee Expert Panel Working Group. J Allergy Clin Immunol

2020;146:1217-70doi: 10.1016/j.jaci.2020.10.003

6 Dempsey OJ. Leukotriene receptor antagonist therapy. Postgrad Med J 2000;76:767-73. doi: 10.1136/pgmj.76.902.767 pmid: 11085767

7 Aaron SD, Vandemheen KL, FitzGerald JM, etalCanadian Respiratory Research Network. Reevaluation of diagnosis in adults with physician-diagnosed asthma. JAMA 2017;317:269-79. doi: 10.1001/jama.2016.19627 pmid: 28114551

8 Aaron SD, Boulet LP, Reddel HK, Gershon AS. Underdiagnosis and overdiagnosis of asthma. Am J Respir Crit Care Med 2018;198:1012-20. doi: 10.1164/rccm.201804-0682CI pmid: 29756989

9 Heaney LG, Robinson DS. Severe asthma treatment: need for characterising patients. Lancet 2005;365:974-6. doi: 10.1016/S0140-6736(05)71087-4 pmid: 15767000

10 Cates C), Karner C. Combination formoterol and budesonide as maintenance and reliever therapy versus current best practice (including inhaled steroid maintenance), for chronic asthma in adults and children. Cochrane Database Syst Rev 2013;4:CD007313.

doi: 10.1002/14651858.CD007313.pub3 pmid: 23633340
11 Kew KM, Karner C, Mindus SM, Ferrara G. Combination formoterol and budesonide as maintenance and reliever therapy versus combination inhaler maintenance for chronic asthma in adults and children. Cochrane Database Syst Rev 2013;12:CD009019.

doi: 10.1002/14651858.CD009019.pub2 pmid: 24343671

12 Papi A, Corradi M, Pigeon-Francisco C, etal. Beclometasone-formoterol as maintenance and reliever treatment in patients with asthma: a double-blind, randomised controlled trial. Lancet Respir Med 2013;1:23-31. doi: 10.1016/S2213-2600(13)70012-2 pmid: 24321801

13 Patel M, Pilcher J, Pritchard A, etalSMART Study Group. Efficacy and safety of maintenance and reliever combination budesonide-formoterol inhaler in patients with asthma at risk of severe exacerbations: a randomised controlled trial. Lancet Respir Med 2013;1:32-42. doi: 10.1016/S2213-2600(13)70007-9 pmid: 24321802

14 Jorup C, Lythgoe D, Bisgaard H. Budesonide/formoterol maintenance and reliever therapy in adolescent patients with asthma. Eur Respir /2018;51:1701688.

doi: 10.1183/13993003.01688-2017 pmid: 29301922

15 Beasley R, Harper J, Bird G, Maijers I, Weatherall M, Pavord ID. Inhaled corticosteroid therapy in adult asthma. Time for a new therapeutic dose terminology. Am I Respir Crit Care Med 2019;199:1471-7. doi: 10.1164/rccm.201810-1868Cl pmid: 30645143

16 Virchow JC, Mehta A, Ljungblad L, Mitfessel HMONICA study group. Add-on montelukast in inadequately controlled asthma patients in a 6-month open-label study: the MONtelukast In Chronic Asthma (MONICA) study. Respir Med 2010;104:644-51. doi: 10.1016/.j.rmed.2009.11.022 pmid: 20031382

17 Pizzichini E, Leff JA, Reiss TF, etal. Montelukast reduces airway eosinophilic inflammation in asthma: a randomized, controlled trial. Eur Respir /1999;14:12-8. doi: 10.1034/j.1399-3003.1999.14a04.x pmid: 10489822

18 Sandrini A, Ferreira IM, Gutierrez C, Jardim JR, Zamel N, Chapman KR. Effect of montelukast on exhaled nitric oxide and nonvolatile markers of inflammation in mild asthma. Chest 2003:124:1334-40. doi: 10.1378/chest.124.4.1334 pmid: 14555563

19 Ramsay CF, Sullivan P, Gizycki M, etal. Montelukast and bronchial inflammation in asthma: a randomised, double-blind placebo-controlled trial. Respir Med 2009:103:995-1003. doi: 10.1016/j.rmed.2009.01.019 pmid: 19249198

20 Currie GP, Lipworth B. Bronchoprotective effects of leukotriene receptor antagonists in asthma: a meta-analysis. Chest 2002;122:146-50. doi: 10.1378/chest.122.1.146 pmid: 12114350

21 Raissy HH, Harkins M, Kelly F, Kelly HW. Pretreatment with albuterol versus montelukast for exercise-induced bronchospasm in children. Pharmacotherapy 2008;28:287-94. doi: 10.1592/phco.28.3.287 pmid: 18294107

22 Lee SY, Kim HB, Kim JH, etal. Responsiveness to montelukast is associated with bronchial hyperresponsiveness and total immunoglobulin $\mathrm{E}$ but not polymorphisms in the leukotriene $\mathrm{C} 4$ synthase and cysteinyl leukotriene receptor 1 genes in Korean children with exercise-induced asthma (EIA). Clin Exp Allergy 2007;37:1487-93 doi: 10.1111/j.1365-2222.2007.02795.x pmid: 17883728

23 Dahlén SE, Malmström K, Nizankowska E, etal. Improvement of aspirin-intolerant asthma by montelukast, a leukotriene antagonist: a randomized, double-blind, placebo-controlled trial. Am J Respir Crit Care Med 2002;165:9-14. doi: 10.1164/ajrccm.165.1.2010080 pmid: 11779723

24 Peters-Golden M, Swern A, Bird SS, Hustad CM, Grant E, Edelman JM. Influence of body mass index on the response to asthma controller agents. Eur Respir J2006;27:495-503. doi: 10.1183/09031936.06.00077205 pmid: 16507848

25 Cates C), Schmidt S, Ferrer M, Sayer B, Waterson S. Inhaled steroids with and without regular salmeterol for asthma: serious adverse events. Cochrane Database Syst Rev2018;12:CD006922 doi: 10.1002/14651858.CD006922.pub4 pmid: 30521673

26 Patel R, Naqvi SA, Griffiths C, Bloom Cl. Systemic adverse effects from inhaled corticosteroid use in asthma: a systematic review. BMJ Open Respir Res 2020;7:e000756. doi: 10.1136/bmjresp-2020-000756 pmid: 33268342

27 Broersen LH, Pereira AM, Jørgensen JO, Dekkers OM. Adrenal insufficiency in corticosteroids use: systematic review and meta-analysis. J Clin Endocrinol Metab 2015;100:2171-80. doi: 10.1210/jc.2015-1218 pmid: 25844620

28 Nelson HS, Weiss ST, Bleecker ER, Yancey SW, Dorinsky PM, Group SSSMART Study Group. The Salmeterol Multicenter Asthma Research Trial: a comparison of usual pharmacotherapy for asthma or usual pharmacotherapy plus salmeterol. Chest 2006;129:15-26. doi: 10.1378/chest.129.1.15 pmid: 16424409

29 Cates C), Wieland LS, Oleszczuk M, Kew KM. Safety of regular formoterol or salmeterol in adults with asthma: an overview of Cochrane reviews. Cochrane Database Syst Rev2014;2:CD010314. doi: 10.1002/14651858.CD010314.pub2 pmid: 24504983

30 Saguil A, Garcia D. Safety of long-acting beta agonists in adults with asthma. Am Fam Physician 2014;90:453-4.pmid: 25369621

31 Busse WW, Bateman ED, Caplan AL, etal. Combined analysis of asthma safety trials of long-acting beta2-agonists. NEnglJ Med2018;378:2497-505. doi: 10.1056/NEJMoa1716868 pmid: 29949492

32 Haarman MG, van Hunsel F, de Vries TW. Adverse drug reactions of montelukast in children and adults. Pharmacol Res Perspect 2017;5:5. doi: 10.1002/prp2.341 pmid: 28971612

33 Schroeder JW, Folci M, Losappio LM, etal. Anti-neutrophil cytoplasmic antibodies positivity and anti-leukotrienes in eosinophilic granulomatosis with polyangiitis: a retrospective monocentric study on 134 Italian patients. Int Arch Allergy Immunol 2019;180:64-71. doi: 10.1159/000500544 pmid: 31189169

34 Ryan D, Murphy A, Ställberg B, Baxter N, Heaney LG. 'SIMPLES': a structured primary care approach to adults with difficult asthma. Prim Care Respir /2013;22:365-73. doi: 10.4104/pcrj.2013.00075 pmid: 23974674 
35 Hew M, Menzies-Gow A, Hull JH, etal. Systematic assessment of difficult-to-treat asthma: principles and perspectives. J Allergy Clin Immunol Pract 2020;8:2222-33. doi: 10.1016/j.jaip.2020.02.036 pmid: 32173508

36 Manning P, Gibson PG, Lasserson TJ. Ciclesonide versus other inhaled steroids for chronic asthma in children and adults. Cochrane Database Syst Rev 2008;2:CD007031.

doi: 10.1002/14651858.CD007031 pmid: 18425977

37 Kocks JWH, Chrystyn H, van der Palen J, etal. Systematic review of association between critical errors in inhalation and health outcomes in asthma and COPD. NPJ Prim Care Respir Med 2018;28:43. doi: 10.1038/s41533-018-0110-x pmid: 30446655

38 Pinnock H, Parke HL, Panagioti M, etalPRISMS and RECURSIVE groups. Systematic meta-review of supported self-management for asthma: a healthcare perspective. BMC Med 2017;15:64. doi: 10.1186/s12916-017-0823-7 pmid: 28302126

39 Stempel DA, Stanford RH, Thwaites R, Price MJ. Cost-efficacy comparison of inhaled fluticasone propionate and budesonide in the treatment of asthma. Clin Ther 2000;22:1562-74. doi: 10.1016/S0149-2918(00)83054-4 pmid: 11192147

40 Johansson G, Andreasson EB, Larsson PE, Vogelmeier CF. Cost effectiveness of budesonide/formoterol for maintenance and reliever therapy versus salmeterol/fluticasone plus salbutamol in the treatment of asthma. Pharmacoeconomics 2006;24:695-708 